\title{
IDENTIFIKASI POTENSI FISIK PESISIR PANTAI WISATA BAHARI KELURAHAN TELUK KABUNG SELATAN KECAMATAN BUNGUS TELUK KABUNG KOTA PADANG
}

\author{
Oleh: \\ Ilhamdi Bagus Perdana*, Yurni Suasti**, Ahyuni** \\ *Mahasiswa S1 Prodi Geografi**Dosen Jurusan Geografi Universitas Negeri Padang \\ Email: ilhamdibagus@gmail.com
}

\begin{abstract}
ABSTRAK
This study aims to (1) Knowing the physical potential supporters South Teluk Kabung Village nautical tourism attractions. (2) Identify the availability of accessibility South Teluk Kabung Village. (3) Identify the availability of means of support South Teluk Kabung Village nautical tourism. (4) Identify the development of marine tourism attraction in South Teluk Kabung Village.

This research is quantitative descriptive, using the techniques of data collection by observation and documentation, as well as using data from institutions Loka Resources Research and Coastal Vulnerability "LPSDKP". The population in this study is the coastal area South Teluk Kabung Village, sampling technique in this research is purposive sampling by taking nine locations scattered South Teluk Kabung Village sample, the sample in this study is a landform marine and alluvial landform.

This study found that: (1) Physical potential South Teluk Kabung Village coast consists of wide beach is 9-18 meters measured from the low water mark to the high water mark, the shape of the beach is a sandy beach, reef conditions found in living keadan, dominant land cover is a shrub and palm trees, beach slope of $0.8 \%$ $-1.45 \%$ by criteria flat beach, ocean depths of 5-40 meters, flow velocity 8:12 to $9: 33 \mathrm{~m} / \mathrm{sec}$, (2) accessibility lower classification with a score of 16, (3) a means moderate classification travel with a score of 5, (4) Things to suite developed marine tourism in coastal areas South Teluk Kabung Village is camping, recreation, snorkeling and diving.
\end{abstract}

Kata Kunci : Physical potential, Coastal, Beaches, Attractions, Accessibility, Means, Tourism

\section{PENDAHULUAN}

Dalam mengkaji sebuah potensi pariwisata pantai, Sumatera Barat merupakan salah satu Provinsi yang mempunyai potensi pariwisata pantai yang cukup menarik dan indah, tapi dalam beberapa hal potensi pariwsata pantai di Sumatera Barat terkendala oleh pengelolaan dan pengembangan yang minim. Sehingga manfaat dari pariwisata tidak bisa tercapai dengan maksimal dan keuntungan dari potensi pariwisata pantai Sumatera Barat tidak begitu memberikan pengaruh terhadap perekonomian dan kehidupan sosial masyrakarat.

Potensi pariwisata pantai di Provinsi Sumatera Barat lebih berfokus pada daerah Kabupeten Pesisir Selatan dan Kota Padang. Pada Kabupaten Pesisir Selatan kita mengenal adanya Kawasan Wisata Mandeh, Kawasan Wisata Mandeh mempunyai potensi dan dalam belakangan wisata Mandeh sudah mulai dilirik oleh pemerintah karena potensi yang ada, berdasarkan berita yang telah dimuat oleh infosumbar.net (11 februari 2015) 
menjelaskan kawasan dipersiapkan untuk menjadi taman laut nasional Mandeh dan menjadi salah satu fokus pengembangan pariwisata bahari di Sumatera Barat, potensi serupa sebenarnya juga terdapat di Kota Padang yaitu pada Kelurahan Teluk Kabung Selatan Kecamatan Bungus Teluk Kabung, Kelurahan Teluk Kabung Selatan berbatasan langsung dengan Kawasan Wisata Mandeh tapi dari segi hal pengembangan di Kelurahan Teluk Kabung Selatan belum terlalu mendapatkan perhatian yang lebih. Hal ini bisa dilihat dari segi transportasi dan sarana prasaran jalan menuju Kelurahan Teluk Kabung Selatan. Transportasi dan sarana prasarana jalan di Kelurahan Teluk Kabung Selatan masih sangat belum memadai untuk dijadikan penunjang dari sebuah kawasan wisata yang maju sehingga menjadikan daerah ini susah untuk disentuh dan digapai oleh wisatawan. Kelurahan Teluk Kabung Selatan mempunyai potensi pariwisata pantai seperti hutan mangrove dan 4 pulau yang saling berdekatan yaitu Pulau Setan, Pulau Pasumpahan, Pulau Sikuai dan Pulau Sirandah. Berdasarkan minat dan tren atraksi wisata pantai saat sekarang banyak wisatawan yang menyukai atraksi snorkeling, berkemah, dan wisata rekreasi. Semua atraksi tersebut ditunjang oleh potensi fisik dari lokasi wisata seperti pada kelurahan Teluk Kabung Selatan. guna mengetahui potensi pengembangan atraksi wisata bahari, diperlukan identifikasi potensi fisik pendukung pengembangangan atraksi wisata bahari.

\section{KAJIAN PUSTAKA}

Istilah pariwisata akan lebih mudah dipahami apabila didahului dengan mengetahui faktor-faktor yang terkandung dalam definisi pariwisata tersebut. Faktor faktor yang dimaksudkan adalah :

1. Perjalanan yang dilakukan untuk sementara waktu.

2. Perjalanan yang dilakukan dari suatu tempat ke tempat lainnya.

3. Perjalanan itu, walaupun apa bentuknya harus selalu dikaitkan dengan rekreasi.

4. Orang yang melakukan perjalanan tersebut tidak mencari nafkah di tempat yang dikunjunginya

Mengkaji sebuah identitas dalam pariwisata kita akan melihat pengaruh positif dan negatif yang akan didapatkan dalam pengembangan sebuah objek pariwisata karena kedua hal tersebut seringkali mempunyai hubungan dan efek langsung terhadap budaya setempat, pariwisata kadang dapat memberi manfaat yang cukup besar baik itu manfaat sosial ekonomi bagi masyarakat, peningkatan pendapatan daerah ataupun taraf hidup masyarakat pada suatu daerah tersebut, tetapi agar tidak terciptanya masalah hal hal negativ dalam kepariwisataan sebuah atraksi atau sebuah objek pariwisata agar dilengkapi dengan pengetahuan budaya lokal ataupun kearifan lokal yaitu dengan cara memperkenalkan kebiasaan beserta adat istiadat setempat dan untuk penduduk setempat diberikan pendidikan untuk memperluas cakrawala berfikir agar terciptanya toleransi terhadap wisatawan dan guna terciptanya hubungan antar budaya ( Przecławski ,1994).

Pantai merupakan sebuah daerah yang berada di tepi perairan yang dipengaruhi oleh air pasang tertinggi dan air surut terendah. Maka dalam menentukan daerah pantai di pengaruhi oleh daerah dataran dan daerah lautan, daerah dataran merupakan daerah yang 
terletak di atas dan di bawah permukaan, daratan dimulai dari batas garis pasang tertinggi sedangkan daerah lautan merupakan daerah yang terletak di atas dan di bawah permukaan laut di mulai dari sisi laut pada garis surut terendah, termasuk dasar laut dan bagian bumi di bawahnya. Garis pantai adalah garis batas pertemuan antara daratan dan air laut, dimana posisi nya tidak tetap dan dapat berpindah sesuai dengan pasang surut air laut dan erosi pantai yang terjadi.

Pesisir merupakan daerah darat yang berada di tepi laut yang masih mendapat pengaruh laut seperti pasang surut, angin laut dan perembesan laut. dalam UU No 27 Tahun 2007 tentang pengelolaan wilayah pesisir dan pulau pulau kecil, Pesisir adalah daerah peralihan antara ekosistem darat dan laut yang dipengaruhi olehperubahan di darat dan laut.

Menurut Thornbury (1969) secara garis besar proses geomorfik yang membentuk rupa bumi terdiri dari proses eksogenetik (epigenetik), endogenetik (hipogenetik), dan ekstraterestrial. Proses eksogenetik terjadi melalui proses gradasi dan aktivitas organisme termasuk manusia. Proses gradasi dapat berupa degradasi yang dapat terjadi melalui proses hancuran iklim (weathering processes), gerakan massa (masswasting), dan erosi. Satuan bentuk lahan maka kita dapat mengetahui satuan bentuk lahan, salah satunya bentuk lahan marin.

\section{METODE PENELITIAN}

Berdasarkan latar belakang dan rumusan masalah maka penelitian ini merupakan penelitian deskriptif kuantitatif, Bersifat deskriptif yaitu suatu metode penelitian yang berusaha untuk mendeskripsikan atau menggambarkan /melukiskan fenomena atau hubungan antar fenomena yang diteliti dengan sistematis faktual dan akurat (Natsir, 1998). Penelitian deskriptif digunakan bertujuan agar peneliti dapat menggambarkan dengan lebih baik potensi fisik pesisir pantai Kelurahan Teluk Kabung Selatan, kuantitatif yaitu pada penelitian ini juga menyajikan data angka angka dan analisis berdasarkan statistik (Sugiyono, 2012). Penelitian kuantitatif digunakan dalam menganalisis data potensi fisik ke dalam bentuk peta.

\section{HASIL DAN PEMBAHASAN Identifikasi Potensi Fisik}

Potensi fisik sebuah kawasan wisata adalah segala hal yang menjadi sumberdaya alam ataupun kemampuan fisiologi dari sebuah kawasan wisata, dalam menganalisis potensi fisik wisata bahari peneliti membagi parameter potensi fisik berdasarkan teknik pengumpulan datanya, potensi fisik yang dikumpulkan melalui observasi lapangan merupakan data primer, potensi fisiknya yaitu: lebar pantai, bentuk pantai, kondisi karang, tutupan lahan. Sedangkan potensi fisik datanya dikumpulkan melalui instansi Loka Penelitian Sumberdaya dan Kerentanan Pesisir merupakan data sekunder, potensi fisiknya yaitu: kemiringan pantai, kecepatan arus, kedalaman laut .

a) Lebar Pantai

Dalam mengukur lebar pantai yang akan digunakan sebagai kawasan wisata, pengukuran dilakukan berdasarkan pasang terendah air laut hingga titik pasang tertinggi air laut di ukur secara manual menggunakan meteran pada 9 lokasi sampel, waktu terjadinya pasang ini 
diketahui berdasarkan penuturan masyrakat, sehingga pasang tertinggi terjadi pukul 05:00 dan pasang tertinggi selanjutnya terjadi pukul 18:30. Pasang terendah pertama terjadi pada pukul 10:15 dan pasang terendah kedua terjadi pada pukul 23:20 maka dapar diukur lebar pantai dengan pada setiap titik nya9 -18 $\mathrm{m}$.

b) Bentuk Pantai

Bentuk pantai merupakan salah satu unsur penting dalam melihat potensi pariwisata bahari, sehingga dalam observasi bentuk pantai pada 9 lokasi sampel di Kelurahan Teluk Kabung Selatan, pantai di Kelurahan Teluk Kabung Selatan merupakan bentuk pantai pasir, bentuk pantai berpasir dapat terjadi karena adanya pengendapan karang dan juga adanya pengendepan dari material muara sungai, sehingga akan terjadinya perbedaan warna pasir karena beda unsur pembentuk pasir pantai.

c) Kondisi Karang

Observasi yang telah dilakukan pada beberapa kawasan laut Kelurahan Teluk Kabung Selatan seperti laut pulau Pasumpahan, laut pantai Batu Jarang, laut pulau Sikuai dan laut pantai Suwarnadwipa, maka kondisi karang pada kawasan ini masih hidup dan mempunyai variasi ikan yang banyak, sehingga dengan kondisi karang pada lokasi penelitian maka hal tersebut sangat potensial untuk dikembangkan dalam salah satu obyek wisata bahari di Kelurahan Teluk Kabung Selatan.

d) Tutupan Lahan

Observasi yang dilakukan pada lokasi penelitian dengan mengambil 9 lokasi sampel penelitian pada dua lokasi berbeda yaitu lokasi pertama Batang Teluk Kabung dan lokasi kedua yaitu Sungai
Pisang di Kelurahan Teluk Kabung Selatan. pada lokasi batang teluk kabung mempunyai tutupan dominan yaitu kelapa dan semak belukar begitu juga di lokasi sungai pisang sehingga pada tutupan lahan seperti ini sangat cocok untuk pengembangan pariwisata bahari, karena himpunan pohon kelapa memberikan keindahan dan kenyamanan sendiri pada sebuah kawasan wisata bahari.

e) Kemiringan Pantai

Data yang didapatkan dari instansi Loka, didapatkan kemiringan 9 lokasi sampel penelitian $0.0014^{\circ}-0.00254^{\circ}$ atau setelah dikonversi dengan satuan persen maka diketahui kemirngan pantai $0,002 \%$ $0,0017 \%$, pada kriteria ini maka kemiringan pantai pada lokasi penelitian di kategorikan datar.

f) Kecepatan Arus

Data hasil pengukuran kecepatan arus yang di dapatkan dari loka penelitian dan pengelola sumber daya pesisir yang diambil berdasarkan 9 titik sampel pada dua lokasi berbeda yaitu Batang Teluk Kabung dan Sungai Pisang maka kecepatan arus pada lokasi penelitian adalah $8.12-9.33 \mathrm{~m} / \mathrm{dt}$

\section{Aksesibilitas Wisata}

\section{a) Aksesibilitas}

Dalam menentukan

kelas

kemampuan aksesibilitas kawasan wisata, maka peneliti melakukan pengambilan data berdasarkan observasi dilapangan dengan teknik pengolahan data pengharkatan (skoring), maka hasil yang didapat dari aksesibilitas kawasan wisata bahari Kelurahan Teluk Kabung Selatan dapat dilihat pada tabel 1 
Tabel 1. Aksesibilitas Kelurahan Teluk Kabung Selatan

\begin{tabular}{|c|c|c|}
\hline No & Indikator & Skor \\
\hline 1 & $\begin{array}{lcc}\text { Kualitas } & \text { Jalan dari } & \text { simpang } \\
\text { Teluk } & \text { Sirih } & \text { menuju } \\
\text { Kelurahan } & \text { Teluk } & \text { Kabung } \\
\text { Selatan } & & \end{array}$ & 2 \\
\hline 2 & $\begin{array}{l}\text { Lebar jalan dari simpang } \\
\text { Teluk Sirih menuju Kelurahan } \\
\text { Teluk Kabung Selatan }\end{array}$ & 2 \\
\hline 3 & $\begin{array}{l}\text { Frekuensi transportasi umum } \\
\text { dari pusat kota menuju } \\
\text { Kelurahan Teluk Kabung } \\
\text { Selatan }\end{array}$ & 2 \\
\hline 4 & $\begin{array}{l}\text { Kelengkapan fasilitas (rambu } \\
\text { - rambu lalulintas) dari pusat } \\
\text { kota menuju Kelurahan Teluk } \\
\text { Kabung Selatan }\end{array}$ & 4 \\
\hline 5 & 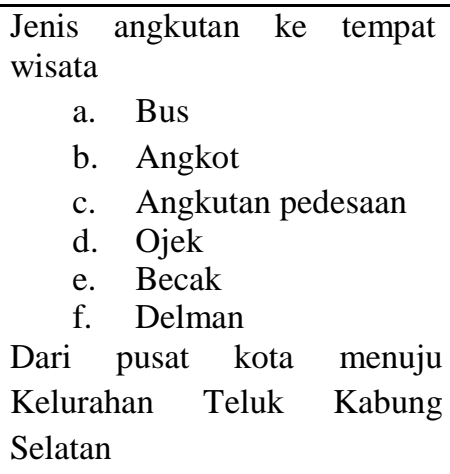 & 2 \\
\hline 6 & $\begin{array}{l}\text { Waktu tempuh dari pusat kota } \\
\text { menuju Kelurahan Teluk } \\
\text { Kabung Selatan }\end{array}$ & 3 \\
\hline 7 & $\begin{array}{l}\text { Biaya transportasi dari pusat } \\
\text { kota menuju Kelurahan Teluk } \\
\text { Kabung Selatan }\end{array}$ & 1 \\
\hline & Jumlah & 16 \\
\hline
\end{tabular}

Sumber : Pengolahan data Primer, 2016

Berdasarkan tabel 1 terlihat kondisi aksesibilitas di kawasan wisata bahari Kelurahan Teluk Kabung Selatan termasuk dalam klasifikasi Rendah dengan skor 16.

\section{b) Sarana Wisata}

Dalam mewujudkan sebuah kawasan wisata yang baik, Berbagai sarana wisata yang harus disediakan di daerah tujuan wisata, hal ini nantinya juga mampu menarik minat dari wisatawan lain untuk berkunjung ke kawasan wisata bahari Kelurahan Teluk kabung Selatan. Dalam menentukan indikator kelengkapan sarana wisata, maka peneliti menggunakan teknik pengharkatan (Scoring), dengan beberapa indikator pariwisata pada tabel dibawah ini

Tabel 2. Sarana wisata KelurahanTeluk Kabung Selatan

\begin{tabular}{|c|c|c|}
\hline No & Indikator & Skor \\
\hline 1 & \begin{tabular}{|ll} 
Sarana yang ada di lokasiwisata : \\
a. & Penginapan \\
b. & Tempatparkir \\
c. & Rumahmakan \\
d. & Pintugerbang \\
e. & Kiosmakanan dan minuman \\
f. & WC umum \\
g. & Poskeamanan \\
h. & Pos P3K \\
i. & Toko souvenir \\
j. & Galeri \\
k. & Padepokan/ \\
& TempatPementasan
\end{tabular} & 4 \\
\hline 2 & $\begin{array}{l}\text { Sarana yang bolehtidakada di lokasi : } \\
\text { a. Hotel berbintang } \\
\text { b. Restoranbesar } \\
\text { c. Tourist information center } \\
\text { d. Shelter }\end{array}$ & 1 \\
\hline \multicolumn{2}{|r|}{ Jumlah } & 5 \\
\hline
\end{tabular}

Sumber: Pengolahan data Primer 2016

Berdasarkan tabel 2 terlihat kondisi sarana di kawasan wisata bahari Kelurahan Teluk Kabung Selatan termasuk dalam Klasifikasi Sedang dengan skor 5.

\section{c) Pengembangan Atraksi Wisata Bahari}

Pada kriteria kesesuaian pengembangan atraksi wisata bahari berdasarkan topografi pantai yaitu "rekreasi dan berkemah" variabel yang di gunakan berdasarkan kriteria pengembangan atraksi wisata bahari, dinyatakan Sesuai dengan kriteria Baik untuk dikembangkan atraksi wisata tersebut pada Kelurahan Teluk Kabung Selatan.

Hal ini didukung dengan tipe pantai pada lokasi penelitian merupakan pantai 
berpasir, pantai berpasir mampunyai drainase yang cukup baik, sehingga mampu dengan cepat meloloskan air dan tidak menimpulkan genangan. Pantai pada lokasi penelitian juga mempunyai kemiringan yang dikategorikan datar dan pantainya memiliki lebar rata - rata 9-18 $\mathrm{m}$, dilihat dari batas vegetasi terakhir hingga pasang surut yang tinggi. Kesesuaian pengembangan atraksi wisata bahari berdasarkan aspek topografi pantai dapat dilihat pada tabel 3

Tabel 3. Kriteria Kesesuaian Pariwisata Bahari topografi pantai

\begin{tabular}{|l|l|l|l|l|}
\hline No & $\begin{array}{l}\text { Atraksi } \\
\text { Bahari }\end{array}$ & $\begin{array}{l}\text { Paramet } \\
\text { er fisik }\end{array}$ & $\begin{array}{l}\text { Temuan } \\
\text { Lapangan }\end{array}$ & $\begin{array}{l}\text { Kesesuai } \\
\text { an (jelek, } \\
\text { Baik) }\end{array}$ \\
\hline 1 & $\begin{array}{l}\text { Berkem } \\
\text { ah }\end{array}$ & $\begin{array}{l}\text { Kemirin } \\
\text { gan } \\
\text { Lereng }\end{array}$ & $\begin{array}{l}0 \%-8 \% \\
\text { (datar - } \\
\text { landai) } \\
\text { Marine } \\
\text { (gisik, } \\
\text { rataan } \\
\text { terumbu) }\end{array}$ & $\begin{array}{l}\text { Baik, } \\
\text { bentuk } \\
\text { lahan 1 } \\
\text { dan 2 } \\
\text { "Gisik } \\
\text { dan } \\
\text { Rataan } \\
\text { Tenambu }\end{array}$ \\
& $\begin{array}{l}\text { lahan } \\
\text { Penutup } \\
\text { Lahan } \\
\text { Material } \\
\text { Permuk } \\
\text { aan } \\
\text { Drainas } \\
\text { e }\end{array}$ & $\begin{array}{l}\text { Pohon } \\
\text { Kelapa }\end{array}$ & Pasir \\
\end{tabular}

\begin{tabular}{|l|l|l|l|l|}
\hline 2 & Rekreasi & $\begin{array}{l}\text { Kemirin } \\
\text { gan } \\
\text { Lereng }\end{array}$ & $\begin{array}{l}\text { 0\% - 8\% } \\
\text { (datar- } \\
\text { landai) } \\
\text { Marine } \\
\text { (gisik, } \\
\text { rataan } \\
\text { terumbu) }\end{array}$ & $\begin{array}{l}\text { Baik } \\
\text { Bentuk } \\
\text { lahan 1 } \\
\text { dan 2 } \\
\text { "Gisik } \\
\text { dan } \\
\text { Rataan } \\
\text { Terumbu } \\
\text { Lahan }\end{array}$ \\
& $\begin{array}{l}\text { Penutup } \\
\text { Lahan } \\
\text { Material } \\
\text { Permuk } \\
\text { aan }\end{array}$ & $\begin{array}{l}\text { Pohon } \\
\text { Kelapa }\end{array}$ & \\
Pasir & \\
\hline
\end{tabular}

Tabel 4. atraksi wisata bahari Berdasarkan Kondisi oseanografi

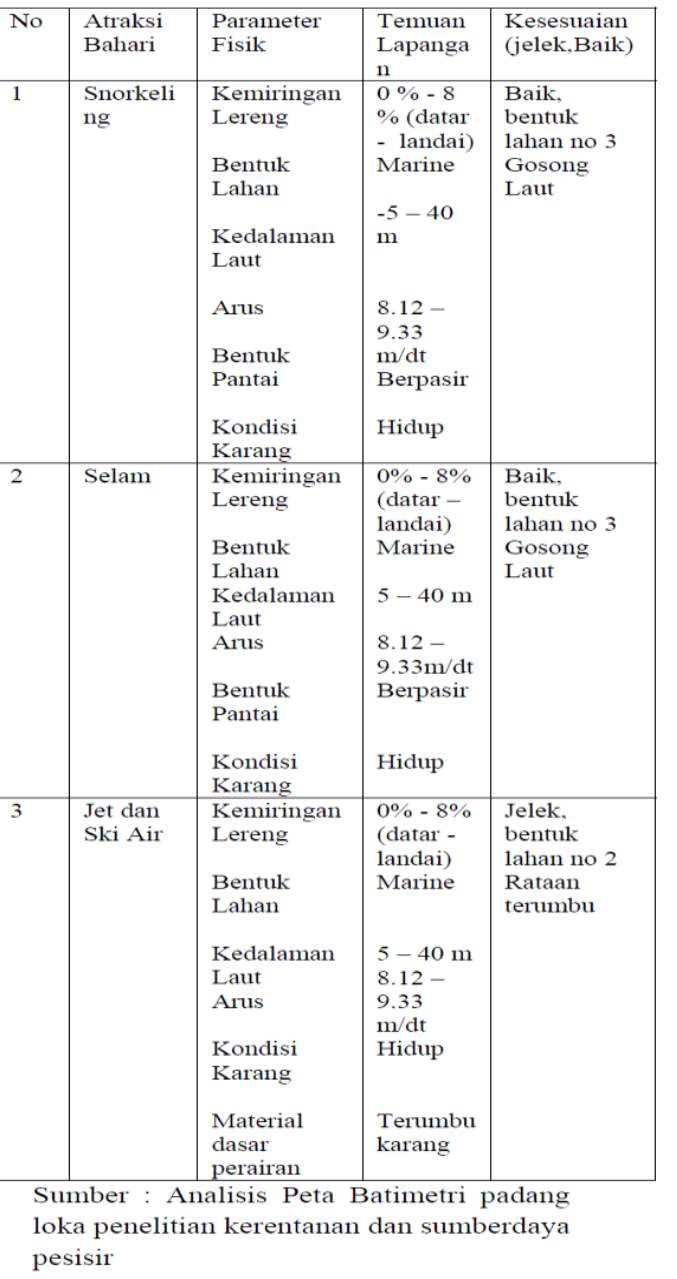


Dalam kriteria pengembangan atraksi wisata bahari berdasarkan kondisi oseanografi dengan atraksi "snorkeling, selam, jet dan ski air" maka berdasarkan kriteria pengembangan atraksi wisata bahari atraksi wisata snorkeling dan selam dinyatakan sesuai dengan kriteria baik, atraksi wisata jet dan ski air dinyatakan Tidak Sesuai dengan kriteria jelek Hal ini didukung dengan data analisis dari peta batimetri dan data loka penelitian kerentanan dan sumberdaya pesisir, berdasarkan peta batimetri Kota Padang, Kelurahan Teluk Kabung Selatan mempunyai ke dalam laut berkisar $5-40$ $\mathrm{m}$, kedalaman maksimal berada pada kawasan pulau Sikuai dan Sirandah, sedangkan pada titik sampel penelitian kedalaman laut berkisar 1,5-9 m.

Kecepatan arus pada lokasi penelitian rata - rata 8.12 - 9.33, hal ini cukup aman dalam melakukan aktivitas dan atraksi pariwisata bahari, sedangkan pulau-pulau kecil mempunyai variabel pengukurannya sendiri, kondisi oseanografi pada pulau pulau kecil mempunyai sedikit perbedaan dengan titik sampel lokasi penelitian, tapi dalam segi kesesuaian pengembangan atraksi wisata bahari, pulau - pulau kecil

\section{SIMPULAN}

Berdasarkan uraian hasil penelitian serta pengolahan data primer dan data sekunder menggunakan beberapa teknik analisis data yaitu overlay, pengharkatan (scoring), dan matching method, maka didapatkan kesimpulan sebagai berikut :

1. Potensi fisik pesisir pantai pendukung wisata bahari di Kelurahan Teluk Kabung Selatan sebagai berikut : a. Lebar Pantai, pada kawasan PesisiR Kelurahan Teluk Kabung Selatan lebar pantai adalah 9-18 $\mathrm{m}$, pengukuran lebar pantai dilakukan pada titik pasang terendah kepada pasang tertinggi dengan skala waktu tertentu terjadinya pasang yang disampaikan oleh masyarakat Kelurahan Teluk Kabung Selatan.

b. Bentuk Pantai, pantai pada kawasan pesisir Kelurahan Teluk Kabung Selatan merupakan bentuk pantai berpasir.

c. Kondisi Karang, terumbu karang di Kelurahan Teluk Kabung Selatan yang tersebar di beberapa tempat seperti Pantai Batu Jarang, Pulau Pasumpahan, Pulau Sikuai, Pulau Ular dan Pulau Setan di identifikasi dengan kondisi masih hidup dan mempunyai variasi ikan yang cukup banyak.

d. Tutupan Lahan, Kelurahan Teluk Kabung Selatan merupakan kelurahan yang lahannya digunakan banyak di tutupi oleh semak belukar dan pohon kelapa.

e. Kemiringan Pantai, Pantai pada Kelurahan Teluk Kabung Selatan Mempunyai kemiringan $0.0014^{\circ}$ $0.00254^{\circ}$ dengan kriteria datar

f. Kecepatan Arus pada Kelurahan Teluk Kabung Selatanberdasarkan data Loka Penelitian Sumberdaya dan Kerentanan Pesisir adalah 8.12 $-9.33 \mathrm{~m} / \mathrm{dt}$

g. Kedalaman Laut, berdasarkan hasil analisis Peta Batimetri Kota Padang maka kedalaman laut di Kelurahan Teluk Kabung Selatan 5-40 m, pada kedalaman tersebut masih termasuk dalam zona neritik. 
2. Aksesibilitas guna memudahkan dan mendukung keterjangkauan ke Kelurahan Teluk Kabung Selatan maka dikemukakan hasil sebagai berikut :

a. Berdasarkan pengolahan data kondisi aksesibilitas wisata, didapatkan kondisi aksesibilitas di kawasan wisata bahari Kelurahan Teluk Kabung Selatan termasuk dalam klasifikasi Rendah dengan skor 16.

b. Berdasarkan pengolahan data kelas jalan, kelas jalan menuju kawasan wisata bahari Kelurahan Teluk Kabung Selatan termasuk dalam klasifikasi Tinggi dengan skor 9, mempunyai potensi yang cukup besar jika di kembangkan atau dilakukan perbaikan pada badan jalan.

3. Sarana pariwisata guna mendukung dan menunjang daya tarik kepada lokasi wisata bahari Kelurahan Teluk Kabung Selatan maka dikemukakan hasil sebagai berikut :

a. Berdasarkan pengolahan data sarana wisata, terlihat kondisi sarana di kawasan wisata bahari Kelurahan Teluk Kabung Selatan termasuk dalam Klasifikasi Sedang dengan skor 5.

b. Berdasarkan pengolahan data sarana penunjang wisata, terlihat kondisi sarana penunjang wisata di kawasan wisata bahari Kelurahan Teluk Kabung Selatan termasuk dalam klasifikasi Tinggi dengan skor 18.

4 pengembangan atraksi wisata bahari berdasarkan topografi pantai yaitu "rekreasi dan berkemah" dinyatakan Sesuai dengan kriteria Baik untuk dikembangkan atraksi wisata tersebut pada Kelurahan Teluk Kabung Selatan. Pada kriteria kesesuaian pengembangan atraksi wisata bahari berdasarkan Keadaan oseanografi yaitu "Selam, Snorkeling" dinyatakan sesuai dengan kriteria Baik sedangkan untuk atraksi wisata Jet dan Ski Air dinyatakan Tidak Sesuai dengan kriteria jelek untuk dikembangkan atraksi wisata tersebut pada Kelurahan Teluk Kabung Selatan

\section{DAFTAR PUSTAKA}

Info sumbar. 2015. "Mandeh Dipersiapkan MenjadiTaman Laut Nasional". (online) diakses tanggal 15 mei 2015

Przeclawski.K.1994. Tourism and world present.wyd. UW. Warsaw

Natsir M. 1998, "Metode Penelitian”Jakarta: Ghalia Indonesia

Sugiyono. 2007. "Metode Penelitian Kuantitatif Kualitatif dan R\&D". Bandung: Alfabeta

Wardhono, Fitri Indra. Ir, Kumpulan Artikel Pariwisata Bahari

Thornbury, William D. Tahun: 1969. Principles of geomorphology.Label: 551.4 THO p. Penerbit: New York : John Wiley

Yoeti, Oka.A. 1996. Pengantar Ilmu Pariwisata. Bandung: Angkasa 